\title{
International and Development Economics
}

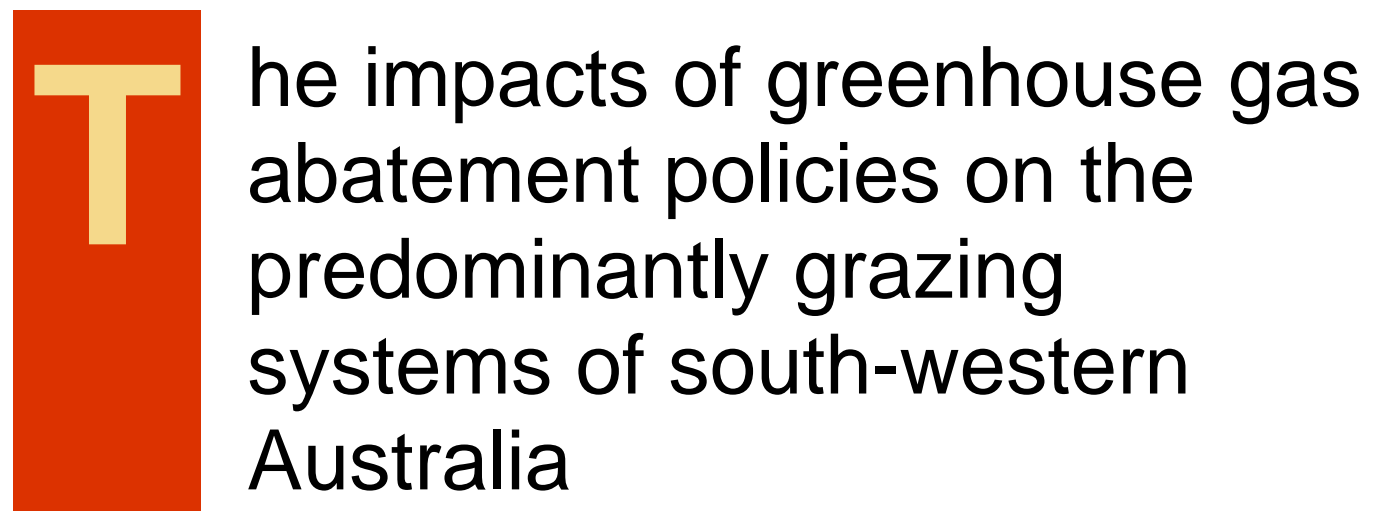

Elizabeth H. Petersen, Steven Schilizzi, David Bennett 02-9

Asia Pacific School of Economics and Government THE AUSTRALIAN NATIONAL UNIVERSITY 


\begin{abstract}
Three policy options for greenhouse gas abatement in the predominantly grazing systems of Western Australia are analysed. The two taxation policies (a tax on total emissions, and a tax on methane emissions only) are only effective at extreme tax rates (\$85/t CO2 equivalents)where farming systems are no longer economically viable. The third policy option, emission restrictions, allows farms to remain profitable at approximately four times greater abatement levels than the taxation policies, and is found to be the most effective and efficient policy option studied. However, it is concluded that the introduction of any farm-level policy for greenhouse gas abatement would be politically unpopular and, in the absence of swift and innovative technological change, would cause the current farming systems to fail and be replaced by alternative land-uses.
\end{abstract}

\title{
Asia Pacific School of Economics and Government THE AUSTRALIAN NATIONAL UNIVERSITY
}

http://apseg.anu.edu.au 


\title{
Short title: The impacts of greenhouse gas abatement policies
}

\section{Full title: The impacts of greenhouse gas abatement policies on the predominantly grazing systems of south-western Australia ${ }^{\dagger}$}

\author{
Elizabeth Petersen ${ }^{\mathrm{a}^{*}}$, Steven Schilizzi ${ }^{\mathrm{b}}$ and David Bennett $\mathrm{c}^{\mathrm{c}}$ \\ ${ }^{a}$ National Centre for Development Studies, The Australian National University, Canberra \\ ACT 0200, Australia \\ ${ }^{b}$ Agricultural and Resource Economics, Faculty of Agriculture, University of Western \\ Australia, Nedlands WA 6907, Australia \\ ${ }^{c}$ NRMC Pty Ltd (Natural Resource Management Consultants), PO Box 217, North \\ Fremantle WA 6159, Australia
}

\begin{abstract}
Three policy options for greenhouse gas abatement in the predominantly grazing systems of Western Australia are analysed. The two taxation policies (a tax on total emissions, and a tax on methane emissions only) are only effective at extreme tax rates $\left(\$ 85 / \mathrm{t} \mathrm{CO}_{2}\right.$ equivalents) where farming systems are no longer economically viable. The third policy option, emission restrictions, allows farms to remain profitable at approximately four times greater abatement levels than the taxation policies, and is found to be the most effective and efficient policy option studied. However, it is concluded that the introduction of any farm-level policy for greenhouse gas abatement would be politically unpopular and, in the absence of swift and innovative technological change, would cause the current farming systems to fail and be replaced by alternative land-uses.
\end{abstract}

Keywords: Greenhouse; Kyoto Protocol; policy analysis; whole-farm modelling

\section{Introduction}

Growing concern about human induced climate change, and the realisation that any reduction in the rate of this change requires international cooperation, has lead governments to take a multilateral approach to the issue. This approach was formalised through the establishment of the United Nations Framework Convention for Climate Change. One of the most significant initiatives of the parties to the Convention is the adoption of the Kyoto Protocol. Australia is a signatory to, but has not yet ratified the Protocol (AGO, 1999b), which requires

\footnotetext{
$\dagger$ The authors acknowledge the contributions of Michael O'Connell and Andrew Bathgate who gave advice concerning the inclusion of greenhouse gas emissions in MIDAS. Also, Robin Nussey and Mark Howden gave helpful comments on earlier versions of the paper. The generous financial support of the Centre for Legumes in Mediterranean Agriculture (CLIMA) and Agriculture Western Australia is also greatly appreciated.

*Corresponding author.Ph: +61 (2) 6125 4953; Fax: +61 (2)6257 2886; email: Liz.Petersen@anu.edu.au
} 
Australia's emissions of greenhouse gases to be no more than 108 percent of 1990 emissions in the first commitment period of 2008-2012 (UNFCCC 1997). Agriculture constitutes 16 percent of the 1990 emissions (which increased to 20 percent by 1996), of which ruminant livestock contribute 70 percent of emissions (AGO, 1999a). Agriculture is the most important source of methane and nitrous oxide emissions, which are both covered under the Protocol. ABARE (1998) states that if appropriate price signals were to be passed to producers about abatement options, it would seem necessary to apply policy measures at the farm level'.

The Australian government has not decided on any action for decreasing greenhouse gas emissions in agriculture (it has encouraged improvements in efficiency in industry with the Greenhouse Challenge and in communities with the "Cool Communities" initiative). Hence, it has not been decided whether policy measures will be applied to agricultural producers. This paper aims to contribute to the climate change policy debate by examining the impacts of farm level policies for greenhouse gas abatement on mixed cropping enterprises in Western Australia. The paper is an analysis of the impacts and efficiency of policy options specifically for the Great Southern region, a region characterised by predominantly grazing farming systems (approximately 85 percent of the farming system is grazed). As will be detailed further, livestock contribute far more greenhouse gas emissions than crops, especially non-irrigated crops. Hence, the region is expected to be sensitive to any greenhouse gas abatement policy.

Farm level policies for greenhouse gas abatement (other than the funding of research and development into technical alternatives) would require planners, firstly, to set aggregate abatement targets, and secondly, to give producers signals and incentives to reach these targets. There are two distinct approaches to producing these signals and incentives (Wills, 1997). The first is for planners to specify allowable levels of emissions for individual emitters together with legal penalties for violations of the specified standards. The second is where planners put a price on emissions thereby signalling the cost of pollution to emitters and allowing emitters to respond freely as they would in a market system. Three policies are considered in this analysis: restrictions on greenhouse gas emissions, a tax on total emissions and a tax on methane emissions only ${ }^{1}$. The first policy complies with the first approach mentioned above and the latter two comply with the second approach ${ }^{2}$. Consideration of government policy for the funding of research and development into technical options for reducing emission is outside the scope of this analysis. Such a policy is discussed as a topic of further research in the Conclusion.

\footnotetext{
${ }^{1}$ Note that these tax and restriction policy options are only three out of the possible range of options.

${ }^{2}$ Incorporating an emission trading system where the farmer can buy and sell emission permits was considered. However, the logistics of the required modelling are complex and were not considered to be worthwhile for the following reasons. First, a tax on emissions is equivalent to the farmers buying emission permits, so half of a trading system is already included. Second, Great Southern farmers are heavily dependent on the sheep enterprise, which will be shown later to be the predominant source of greenhouse gas emissions. The price of selling a permit would have to be significantly higher than predicted permit prices for the Great Southern farmers to sacrifice sheep income to sell emissions permits. Hence, completing the complex modelling to include permit trading was not considered justifiable.
} 
The structure of the article is as follows. The model used in the analysis is described in Section 2. The results of the analysis are reported and discussed in Section 3. The paper concludes with a brief summary and a discussion of further research.

\section{Methods}

The instrument of analysis is MIDAS (Model of an Integrated Dryland Agricultural System) (Kingwell and Pannell, 1987; Morrison et al., 1986). MIDAS is a linear-programming model of a steady-state single period representation of a farming system and was constructed by a multidisciplinary team of researchers, advisers, farm management consultants and farmers. MIDAS was originally developed for the Merredin region of Western Australia, but has since been calibrated for several regions of the wool and wheat belts of Western Australia (see Figure 1) and continues to be used in analysing issues in farm management (Schmidt and Pannell, 1996), agricultural policy (Morrison and Young, 1991), agricultural extension (Marsh and Pannell, 1998) and research (Pannell, 1999). MIDAS was chosen to be used in this study as it is a whole-farm model that includes the relevant biological complexities and interactions between enterprises in a typical wheat belt farming system (described in Section 2.1.4). These complexities and interactions are difficult to capture without a whole-farm modelling framework (Pannell, 1996).

[Figure 1]

The Great Southern version of MIDAS, the version used for this analysis, can be applied to an area of approximately one million hectares in the shires of Kojonup, Boyup Brook, West Arthur, Cranbrook and Williams. Statistics for the region and the Western Australian agricultural region as a whole are presented in Table 1. The following subsection is a brief description of the Great Southern MIDAS (GSM) model, but readers are referred to Morrison and Young (1991) and Young (1995) for detailed expositions of the nature and structure of the model. A description of how the model was further developed to include greenhouse gas emissions is reported in Section 2.2.

\subsection{The Great Southern MIDAS}

[Table 1]

The climate in the Great Southern region is typically Mediterranean with mild wet winters and hot dry summers. Annual average rainfall is between 500 and $600 \mathrm{~mm}$, mostly falling in winter from the end of April to the beginning of November. There are approximately 1000 farms in the area with an average farm size of 1100 hectares (ABS, 1997). To reflect these conditions, GSM assumes a farm size of 1000 hectares. MIDAS optimises, using a profit maximising function, a mix of livestock (sheep) and crop enterprises (cereals, lupins, field peas and canola), with typically around 15 percent of land cropped. The farm operations are highly mechanised, with a fixed complement of machinery.

Soil types are modelled in five land management units (LMUs) that are assumed to be internally homogeneous (Table 2). Implicitly, soils within a LMU have the same land use suitability and the whole LMU responds similarly to any given management. The LMUs display a range of fertility levels. The saline and waterlogged LMUs (1 and 2) that comprise 25 percent of total area are relatively infertile and are usually not cropped under normal circumstances. LMU4 (50 percent of farm area) is the most suitable LMU for crop production. The rotational options represented in GSM are listed in Table 3. Canola production is only possible on the heavier LMUs (4 and 5: 70\% of farm area) while wheat, barley, oats, lupins, field peas and pasture are possible on all LMUs, although crops are unlikely to be grown on LMUs $1 \& 2$. 
[Table 2]

[Table 3]

\subsubsection{Pasture enterprise}

Pasture growth rates are dependent on the LMU, time of year, the amount grazed, rate of deterioration and the extent of trampling by livestock. The quality of pasture declines over the growing season, especially through the summer drought (November to April) due to the leaching of nutrients from senesced pasture and the decay of dry matter. The botanical composition of the sward varies considerably across the paddocks. It is assumed in GSM that pastures contain typically 30 percent volunteer annual grasses (barley grass, brome grass), 30 percent herbs (capeweed, geranium), and 40 percent introduced annual legumes (subterranean clover (Trifolium subterranean) and annual medics (Medicago spp)).

\subsubsection{Livestock enterprise}

Livestock is modelled as a self-replacing merino sheep flock kept for wool and meat production. Fifty-nine classes of sheep are described for different ages, time of sale and gender. Lambing can occur in late autumn or early spring, and complementary shearing takes place twice a year in March and September. Liveweights are influence by the availability and quality of feed from a range of sources (pasture, supplementary feeding and stubble grazing).

The year is divided up into ten feed periods of varying length, depending on the availability and quality of feed as well as the sheep's energy demands. Sheep subsist on green annual pastures during late winter, spring and early summer. During the other times they subsist on dry annual pastures (in summer and autumn), crop stubble (also in summer and autumn) and supplementary feeding which may be bought or retained on farm (hay in summer and lupins, oats and barley in autumn). Grain, hay and silage are stored on farm and can be fed when pasture availability is low to ensure the supply of energy to sheep is adequate to maintain sufficient live-weight, in particular for pregnant ewes. The feed supply of the sheep is influenced by two factors: the energy requirements of the sheep in each period, and the energy concentration of the feed (as energy concentration and digestibility limit intake capacities). Costs associated with sheep production include purchase, selling, shearing, crutching, vaccinating, drenching and other animal husbandry costs.

\subsubsection{Crop enterprises}

Wheat, barley, oats, lupins, field peas and canola are grown in rotation with pasture. Continuous cropping rotations are not sustainable in the Great Southern region due to low soil fertility. To reflect conditions in the Great Southern region, the method of crop preparation assumed in MIDAS is reduced or minimum tillage with one single working up operation. Time of sowing is dependent on rainfall and management strategy. However, most crops are sown between April and July.

\subsubsection{Interdependencies of enterprises}


Some interdependencies of enterprises are included. GSM includes three main interdependencies: rotational benefits between phases in a rotation; the grazing of stubble by sheep $^{3}$; and the subsequent grazing of remnant grain in the paddock after harvest.

\subsubsection{Profit-maximisation objective}

The model is based solely on expected values ${ }^{4}$ and therefore assumes risk-neutral decisionmaking. GSM is a steady-state model assuming an expected weather-year. The objective is profit maximisation, as this remains the main driver for decision-making by Australian farmers (Pannell et al., 1998). However, other managerial goals and behaviour is implicitly incorporated into the model. Examples are the need to finish harvest in early January (typically farmers are on holiday off-farm in mid-January for a few weeks), soil conservation attitudes (restrictions on the removal of pasture by the grazing of sheep) and animal welfare considerations (not allowing the sheep liveweight condition to fall to a level that would cause the sheep to be classed as being in poor condition).

The output of the model is information on a set of profit-maximising enterprises and rotational activities as well as shadow price information about the marginal value of farm resources and alternative enterprises, or rotational options. Farm profit is calculated as a net return to capital and management. It equates to income left over from production receipts after deducting all operating costs, overhead costs, depreciation and opportunity costs associated with farm assets (exclusive of land).

\subsection{The modelling of greenhouse gas emissions}

The National Greenhouse Gas Inventory (NGGI) Committee of the Australian Greenhouse Office has produced a series of workbooks which give human induced greenhouse gas emission levels and calculations for measurement for six sectors: energy, industrial processes, solvent and other product use, agriculture, land use change and forestry, and waste (NGGI, 1998a; NGGI, 1998b; NGGI, 1998c; NGGI, 1998d; NGGI, 1998e; NGGI, 1998f; NGGI, 1998g; NGGI, 1998h). This methodology identifies the sources of greenhouse gas emissions from the mixed crop-livestock agricultural sector to be sheep emissions, livestock excreta, nitrous oxide emissions from microbial and chemical transformations in the soil, fuel use, field burning of agricultural residues and land-use change. Each of these sources was considered for inclusion of the GSM as discussed in what follows.

Methane emissions from sheep are modelled according to the NGGI methodology for livestock as described in Section 2.2.1 ${ }^{5}$. Methane emissions from livestock excreta were considered to be negligible as anaerobic conditions (a prerequisite for methane production) exist only under concentrated sites, such as feedlots. Sheep in the Great Southern are grazed in open pastures where anaerobic conditions do not exist. Nitrous oxide emitted from

\footnotetext{
${ }^{3}$ Sheep are assumed to preferentially graze the stubble, selecting grain first followed by leaf, pods (if available), chaff and stem.

${ }^{4}$ The expected value is the first moment of the probability distribution.

${ }^{5}$ Carbon dioxide emissions from sheep are a product of respiration and as such are not accounted for in the Inventory.
} 
microbial and chemical transformations in the soil involves ammonium, nitrite and nitrate. These nitrogen sources are added to the soil through fertiliser, sheep excreta, inorganic nitrogen compounds from the atmosphere, and mineralisation of organic nitrogen in the soil (NGGI, 1998f). Nitrous oxide emissions from nitrogen fertiliser applications are included in the model as described in Section 2.2.2. The rate of mineralisation of organic nitrogen in the soil is increased through soil disturbances, mainly crop cultivation. However, such emissions are very small (approximately $0.3 \mathrm{~kg} \mathrm{~N}_{2} \mathrm{O}$ per hectare) (NGGI, 1998f). Given that an average of only 15 percent of the farm is cropped in the Great Southern, emissions from this source were considered too small to include in GSM. Modelling emissions from fuel use and field burning of agricultural residues (stubble burning) are described in Sections 2.3.3 and 2.3.4. It is assumed that no land on the farm is cleared for agriculture, nor is any land planted to managed forests. Hence, emissions due to changes in land use are also assumed to be negligible.

In summary, greenhouse gases are assumed to be emitted from four main sources: sheep, nitrogenous fertiliser application, fuel use and stubble burning. Different greenhouse gases are produced from these four sources; methane $\left(\mathrm{CH}_{4}\right)$ is emitted from sheep, nitrous oxide $\left(\mathrm{N}_{2} \mathrm{O}\right)$ from nitrogenous fertilisers, carbon dioxide $\left(\mathrm{CO}_{2}\right)$ from fuel use and a range of compounds from stubble burning. For modelling purposes, emissions are converted to $\mathrm{CO}_{2}$ equivalents through multiplication by their global warming potential, using the aggregation principle. These relative potentials are shown in Table 4.

\subsubsection{Sheep emissions}

[Table 4]

Greenhouse gas emissions from sheep are modelled according to the NGGI methodology for livestock published by the Australian Greenhouse Office (NGGI, 1998e). It predicts methane production from intake alone. This limitation is considered acceptable given that Howden et al. (1994) found that 87 percent of the variation in methane production can be explained through measurement of dry matter intake through the following relationship:

$$
M_{i j k}=I_{i j k} * 0.0188+0.00158
$$

where $M_{i j k}=$ methane production $(\mathrm{kg} / \mathrm{head} /$ day $)$

$I_{i j k}=$ actual intake of a sheep ( $\mathrm{kg}$ dry matter/head/day)

Intake levels in the model are not set, rather they are optimised given energy requirements of the sheep flock, energy concentrations of the feed and expected prices of wool, meat and feed. This flexibility allows for the examination of alternative feed mixes given different costs of greenhouse gas emissions.

\subsubsection{Nitrogenous fertiliser application}

$\mathrm{N}_{2} \mathrm{O}$ emissions from nitrogenous fertiliser application are calculated as the product of the amount of nitrogen per unit of the fertiliser, the proportion emitted from the source (emission factor) and the conversion factor from nitrogen to $\mathrm{N}_{2} \mathrm{O}$. Three nitrogenous fertilisers are applied in the Great Southern region: DAP, Urea and Agras. The calculation of $\mathrm{N}_{2} \mathrm{O}$ emissions per tonne of applied fertiliser is shown in Table 5.

[Table 5]

\subsubsection{Fuel use}


Fuel is burned in a number of farm operations. Typically, petrol is used for harvest cartage and diesel is used for all other operations (i.e. seeding and harvesting). Assumptions regarding fuel use per hectare of operation and fuel burning factors are presented in Tables 6 and 7. The quantity of fuel use is multiplied by three factors to calculate the quantity of $\mathrm{CO}_{2}$ emitted per hectare of the operation (Table 7). These factors are the energy density (to obtain a volume of energy burned per hectare of fuel use), a factor representing the volume of $\mathrm{CO}_{2}$ emitted per MJ of energy of fuel burned, and the proportion oxidised. The amount of fuel used in the model is not fixed; rather it is optimised given the relative profitabilities of each of the farm operations.

[Table 6]

[Table 7]

\subsubsection{Stubble burning}

Stubble burning takes place in either late autumn or spring. As a form of land management, the burning of stubble is increasingly being replaced by stubble retention that conserves nutrients and reduces erosion. Nevertheless, approximately 23 percent of Western Australian crop stubble is burned annually (NGGI, 1998f).

The following equation is used to estimate greenhouse gas emissions from stubble burning (NGGI, 1998f):

$$
M_{i}=P_{i} * R_{i} * S_{i} * D M_{i} * Z_{i}^{*} F_{i}
$$

where $M_{i}=$ annual mass of residue burnt from crop for gas $i(\mathrm{~kg})$

$P_{i}=$ annual production of crop $(\mathrm{kg})$

$R_{i}=$ residue to crop ratio ( $\mathrm{kg}$ crop residue $/ \mathrm{kg}$ crop)

$S_{i}=$ fraction of crop residue remaining at time of burning

$D M_{i}=$ dry matter content (k dry weight $/ \mathrm{kg}$ crop residue)

$Z_{i}=$ burning efficiency (fuel burnt/fuel load) for residue from crop

$F_{i}=$ fraction of the annual production of crop that is burnt (ha burnt/ha harvested)

The mass of stubble burnt is converted to an emission of $\mathrm{CO}, \mathrm{CH}_{4}, \mathrm{~N}_{2} \mathrm{O}$, other nitrogen oxides $\left(\mathrm{NO}_{\mathrm{x}}\right)$ or non-methane volatile organic compounds (NMVOC) by multiplying the carbon content of the fuel by an emission factor as shown by equation (3) (NGGI, 1998f):

$\operatorname{TOTAL}_{i}=M_{i} * C C_{i} * N C_{i} * E_{i} * C_{i}$

where $\operatorname{TOTAL}_{i}=$ annual emission of gas $i$ from burning crop residue $(\mathrm{kg})$

$\mathrm{CC}_{i}=$ mass fraction of carbon in crop residue

$\mathrm{NC}_{i}=$ nitrogen to carbon ratio in crop residue

$\mathrm{E}_{i}=$ emission factor for gas $i$ from crop residue (kg element $i / \mathrm{kg}$ element burnt)

$\mathrm{C}_{i}=$ factor to convert from elemental mass of species $i$ to molecular mass

Data for the factors defined in the previous two equations are presented in Tables 8 and 9.

[Table 8]

[Table 9]

\subsubsection{Optimisation procedure and sensitivity analysis}


The outputs from the linear programming optimisation procedures contained in the model indicate the optimal levels of enterprise and rotational activities given $\mathrm{CO}_{2}$ equivalent emissions from these four components (and interactions with other enterprises) and the cost of the emissions. The predicted cost of emissions varies significantly depending on the type and extent of the marketing procedure. Predicted $\mathrm{CO}_{2}$ equivalent costs assuming an emission trading system with different trading scenarios are presented in Table 10. Given the sensitivity on the type and extent of trading, for the purpose of this study it is assumed that the cost of the emissions in the first commitment period will be valued at between $\$ 10$ and $\$ 50 / \mathrm{CO}_{2}$ equivalent (in current Australian dollars). Hence, no one emission cost is assumed in this analysis but a range of costs will be analysed.

\section{Results and Discussion}

[Table 10]

This section comprises two parts. The first (Section 3.1) is an examination of the impact of greenhouse gas reduction policies on the Great Southern farming system, using a tax on total emissions as a baseline example. The second (Section 3.2) is a comparison of the impact and effectiveness of three different policy options, namely a tax on emissions (as discussed in Section 3.1), emission restrictions and a tax on methane emissions only.

\subsection{The impact of a tax on greenhouse gas emissions on the Great Southern farming system}

Consider first the impact of a tax on greenhouse gas emissions on farm profit. This impact for four different wool prices is displayed in Figure 2. Profits are sensitive to wool price, which is not surprising given the dependence of the Great Southern farming system on wool production. There is a linear relationship between profit and the taxation level ${ }^{6}$. The tax level for which the model falls to zero-profit varies from $\$ 12 / t \mathrm{CO}_{2}$ equivalents $\left(\mathrm{CO}_{2}\right.$-e $)$ to $\$ 43 / \mathrm{t} \mathrm{CO}_{2}$-e for wool prices varying between $300 \mathrm{c} / \mathrm{kg}$ greasy and $450 \mathrm{c} / \mathrm{kg}$ greasy respectively. The medium term forecast for wool price is currently $400 \mathrm{c} / \mathrm{kg}$ greasy ${ }^{7}$ for which the zero-profit tax on the emission is $\$ 33 / \mathrm{t} \mathrm{CO}_{2}-\mathrm{e}$. This tax level is similar to the forecast emission price if developed country trading of permits is introduced (see Table 10). Hence, in the absence of the prior allocation of emission permits, emissions trading for Great Southern farmers would make the farm unprofitable. However, if global trading of permits exist, the permit price is likely to be substantially lower (approximately $\$ 15 / \mathrm{t} \mathrm{CO}_{2}$-e) presenting an economically viable policy for Great Southern farmers.

[Figure 2]

The impact of a tax on emissions on the level of total emissions and the percentage of these emissions from sheep is demonstrated in Figure 3. In the absence of an emissions tax policy, the model farm emits approximately 1745 tonnes of $\mathrm{CO}_{2}$-e annually. The vast majority of emissions (97 percent) are from sheep in the form of methane production. A much smaller proportion is from fertiliser use (1.8 percent in the form of nitrous oxide), fuel use $(0.75$ percent in the form of carbon dioxide) and stubble burning ( 0.53 percent in various forms). In the presence of a tax on emissions, the level of total emissions and the proportion of these emissions from sheep decrease slightly. As crop production is a relatively more efficient

\footnotetext{
${ }^{6}$ Note that, due to this dependence on wool production, a tax on greenhouse gas emissions is equivalent to placing an export tax on wool or lambs.

${ }^{7}$ This was the forecast at the time the paper was written.
} 
enterprise in terms of greenhouse gas abatement than sheep production, this occurs as the system substitutes out of sheep production into crop production with increasing tax levels.

[Figure 3]

When considering tax levels that are comparable to the price of a tradeable permit $(\$ 10-\$ 50 / \mathrm{t}$ $\mathrm{CO}_{2}$-e), unlike profitability, the level of emissions does not change significantly. Imposing a $\$ 33 / \mathrm{t} \mathrm{CO}_{2}$-e tax rate (the zero-profit tax rate) and a $\$ 50 / \mathrm{t} \mathrm{CO}_{2}$-e tax rate (maximum potential price of a tradeable permit) only causes a decrease in emissions of 10 and 12 percent respectively. Model results indicate that the imposed tax would have to increase to $\$ 85 / \mathrm{t}$ $\mathrm{CO}_{2}$-e, nearly three times the zero-profit value of $\$ 33 / \mathrm{tCO}_{2}-\mathrm{e}$, before substantial changes in emissions are experienced. This inelasticity of emission abatement is due to the dependence of the current system on sheep production. The region is typically not suited to crop production. Hence, the substitution into crops only occurs when the tax on emissions is very high $^{8}$.

Decreases in total emissions with increasing tax rate correspond directly with decreases in the proportion of the farm in pasture (Figures 4 and 5) and sheep numbers (Figure 6). These figures will now be discussed individually. Consider first the effect of a tax on greenhouse gas emissions on the proportion of each LMU in pasture (Figure 4). In the absence of the tax, 100 percent of LMUs 1, 2, 3 and 5, and 72 percent of LMU4 are in pasture (the majority of LMU4 is sown to the 4PCC rotation). The maximum sustainable crop percentage for each LMU is 50 percent where the units are sown to the pasture-cereal rotation (PC), hence the maximum sustainable cropping percentage for the whole farm is 50 percent. However, as LMUs 1, 2 and (to lesser extent) 3 are highly unsuitable for crop production, these units are not sown to crop under realistic tax rates. The other LMUs substitute from pasture to crop production depending on their relative crop-pasture production suitabilities. LMU4 drops from 70 percent to 63 percent pasture between tax levels of $\$ 25$ and $\$ 40 / \mathrm{t} \mathrm{CO}_{2}-\mathrm{e}$, and LMU5 drops from 100 percent to 66 percent pasture between $\$ 15$ and $\$ 50 / \mathrm{tCO}_{2}$-e.

[Figure 4]

The change in pasture percentage for the whole farm with different levels of a tax on emissions is presented in Figure 5. In the absence of a tax on emissions, 85 percent of the farm is in pasture. In the presence of a tax on emissions, the percentage of the farm in pasture decreases with increasing tax levels. Significant decreases occur at a tax of $\$ 15 / \mathrm{t}$ $\mathrm{CO}_{2}$-e where the percentage of pasture on LMU5 drops sharply from 100 percent to 70 percent. At the zero-profit tax rate $\left(\$ 33 / \mathrm{t} \mathrm{CO}_{2}-\mathrm{e}\right)$, the percentage pasture has decreased only marginally from 85 percent to 79 percent $^{9}$.

[Figure 5]

\footnotetext{
${ }^{8}$ This inelasticity of abatement illustrates that substitution into cropping so that emission permits can be sold will only occur at extremely high permit prices. This gives justification for not modelling a tradeable emission permit system.
}

\footnotetext{
${ }^{9}$ Note that significant substitution from pasture to crop production will cause significant amounts of soil carbon to be emitted. These emissions are not included here, as soil carbon is not as yet included in the Protocol. However, if these emissions were to be included, large soil carbon emissions only occur after the current system is made unprofitable at which stage the farmer is put out of business. Hence, not accounting for these emissions does not detract from the analysis.
} 
The effect of an emissions tax on sheep numbers is presented in Figure 6. In the absence of a tax on emissions, 8260 dry sheep equivalents (DSE) are run on the farm ${ }^{10}$. Sheep numbers drop slightly at a tax rate of $\$ 15 / \mathrm{t} \mathrm{CO}_{2}$-e. This corresponds with a fall in the percentage of LMU5 in pasture. At the zero-profit tax rate sheep numbers drop to 7500 DSE, a 9 percent drop (and profit falls by 11 times as much). Small decreases in sheep numbers cause substantial profit decreases giving further evidence for the dependence of the system on sheep and the economies in flock size. A tax on emissions has a similar impact on farm management and performance as the drop in wool prices of the early 1990s. Wool prices fell from an average of $545 \mathrm{c} / \mathrm{kg}$ greasy in $1989-90$ to 390c/kg greasy in 1990-91, a 28 percent fall. As a result, sheep numbers and farm profit in the Great Southern region fell dramatically (ABARE, 1992).

[Figure 6]

In concluding this section, it is clear that a tax on greenhouse gas emissions is a drastic policy option for greenhouse gas abatement with the current farming system. The introduction of this policy would be extremely unpopular with the farming community and, in the absence of swift and innovative technical advancement which provides farmers in the Great Southern region with viable alternatives for greenhouse gas abatement, a tax on emissions would cause the current farming system to fail and be replaced by alternative enterprises.

\subsection{Comparison of policy options}

Three policy options are compared in this section: emission restrictions, the tax on total emissions discussed in the previous section, and a tax on methane emissions only. Consider now the emission restriction policy where the farmer is legally required to restrict emissions. This policy has the same managerial outcomes as providing a subsidy for abatement. The marginal cost to the farmer of restricting emissions is the size of the subsidy needed to be paid to achieve the same decrease in emissions. However, financial outcomes would differ depending on whether the farmer is compensated for restricting emissions, as would be the case for a subsidy policy. The marginal cost curve for emission abatement is presented in Figure 7. As expected, the marginal cost of abatement increases as the level of abatement increases. This indicates that the cheapest methods for abatement are adopted first. As the level of required abatement increases, the system adopts the more expensive methods. At a marginal cost of $\$ 33 / \mathrm{t} \mathrm{CO}$-e (the zero-profit tax rate), emissions are reduced by $250 \mathrm{t} \mathrm{CO}_{2}$-e (14 percent compared with 8 percent with the taxation policy).

[Figure 7]

The marginal cost curve exhibits a threshold at approximately 550 tonnes of $\mathrm{CO}_{2}$-e that can be explained in Figure 8. The percentage of each LMU in pasture for different levels of abatement is presented. Similar to Figure 4, in the absence of a greenhouse gas abatement policy, 100 percent of LMUs 1, 2, 3 and 5, and 72 percent of LMU4 are in pasture. At relatively low levels of greenhouse gas abatement LMUs 5 and 4 are the first to substitute into cropping, a trend that is also similar to that presented in Figure 4. However, unlike Figure 4, at high levels of abatement LMUs 3 and 2, which are typically unsuitable to crop production, are forced to substitute into cropping. This difference occurs because the farming system is more profitable for each level of $\mathrm{CO}_{2}$ abatement under the emission restriction policy rather than the tax on emission policy as the farm is not financially penalised for its

\footnotetext{
${ }^{10}$ Sheep numbers in February are used for comparison even though sheep numbers change during the season. February was chosen as, in GSM, the first shearing of the year occurs in this month, after which the first sheep sales are made.
} 
greenhouse gas emissions. The system can afford to decrease the pasture percentage on LMU2 in order to decrease $\mathrm{CO}_{2}$ emissions at a greater rate. However, LMU1, which is even less suitable to crop production than LMU2, is still not cropped. The threshold observed in Figure 7 occurs where almost the maximum amount of pasture is substituted for crop on LMUs 3, 4 and 5.

[Figure 8]

Consider the total cost to the regulator if farmers are subsidised for restricting emissions. Consider an abatement level of 10 percent $\left(175 \mathrm{t} \mathrm{CO}_{2}-\mathrm{e}\right)$. From Figure 7 it can be seen that the subsidy would have to be approximately $\$ 20 / \mathrm{t} \mathrm{CO}_{2}$-e, hence the total cost for this farm to abate $175 \mathrm{t} \mathrm{CO}_{2}$-e is $\$ 3,500$ per year. Furthermore, over the one million hectares of the Great Southern regions (as the farm size is 1000 hectares, this equates to 1000 farms in the region), the total cost to the regulator is $\$ 3.5$ million dollars per year. This is a substantial quantity of money given that only a small proportion of Australia's total emissions are abated (10 percent), and the Great Southern region is only a small proportion of Australia's agricultural area.

Now consider a comparison of all three policy options. Sheep numbers and pasture area for each policy option do not vary significantly from one another across different levels of abatement. However, farm profit for each policy option does vary according to Figure 9. An emission restriction policy allows the farm to remain more profitable for all levels of abatement than the taxing policies as farmers are not financially penalised for the farm's emissions, but are simply restricted in the level of emissions allowed. With a tax on methane emissions only, farm profit is, of course, greater than that under the tax on all emissions. As illustrated in Table 11, the zero-profit level of abatement for the restriction on emission policy is $850 \mathrm{t} \mathrm{CO}_{2}$-e (48 percent abatement), for the tax on methane emissions policy is $180 \mathrm{t}$ $\mathrm{CO}_{2}$-e (10 percent abatement), and for the tax on all emissions policy is $150 \mathrm{t} \mathrm{CO}_{2}$-e (8 percent abatement). Hence, restrictions on emissions allows the farm to remain profitable for five times the abatement levels of the taxation policies.

[Figure 9]

[Table 11]

Emission taxes make use of emitter's private information about their marginal benefits from emissions and, hence, their marginal cost of abatement. Therefore, they achieve least-cost emission reductions. This is not the case for emission restrictions where abatement is rarely achieved at least cost. However, policy-makers generally prefer emission restrictions due to their familiarity, flexibility, and general ability to achieve their objective. Furthermore, if the farmers in the Great Southern region were to be fully compensated for loss of income due to the restrictions, it would cost the regulator approximately $A \$ 3.5$ million a year to achieve approximately 50 percent abatement. It is concluded that if international pressure for greenhouse gas abatement increases to a level such that price signals for such abatement need to be passed on to agricultural producers, other than investing in technical change, a restriction on emissions policy is the most effective measure for doing this, at least for livestock dominant systems. However, if farmers were to be fully compensated it would be extremely costly for the regulator ${ }^{11}$.

\footnotetext{
${ }^{11}$ Even if farmers in the Great Southern region were to be compensated for only one-half of their loss of income due to the restrictions, it would still be extremely costly to the regulator.
} 


\section{Conclusion}

The impact of farm-level policies for greenhouse gas abatement on mixed cropping enterprises of Western Australia is examined. The study focuses on the Great Southern region, a region that supports predominantly grazed farming systems. Three policy options are compared, namely a tax on greenhouse gas emissions, a tax on methane gas emissions only, and restrictions on the amount of emissions allowed. A number of conclusions may be drawn from the study. First, the impact of the policies is extremely sensitive to wool price due to the dependence of the current system on sheep production. Second, in the absence of an abatement policy, the vast majority of emissions are from sheep (97 percent), with smaller proportions of emissions from fertiliser use, fuel use and stubble burning. Third, with the introduction of a taxation policy, under a range of tax levels, total emissions do not change substantially. Imposing a $\$ 50 / \mathrm{t}$ carbon dioxide equivalent tax rate (the maximum potential price of a tradeable permit) only causes a decrease in emissions of 12 percent. This inelasticity of abatement again indicates the dependence of the current system on sheep production. Significant substitution out of sheep into crop production only occurs at extremely high tax rates ( $\$ 85 / \mathrm{t}$ carbon dioxide equivalents). The Great Southern farming system is made unprofitable at relatively low tax rates ( $\$ 33 / \mathrm{t}$ carbon dioxide equivalents). Hence, the taxation policies only become effective after farmers have been driven out of business. Note that at this zero-profit tax rate, emissions are decreased by only 10 percent, the percentage of pasture is decreased by only 19 percent and sheep numbers drop by only 9 percent.

The three policies compared did not significantly differ in optimal sheep numbers or pasture areas across levels of abatement. However, under the restriction on emissions, the farm remained profitable for five times the abatement levels of the taxation policies. Hence, placing restrictions on emissions without compensation is probably the most effective and economically viable measure considered. Although, if farmers were compensated for income lost, it would cost the regulator approximately $\mathrm{A} \$ 3.5$ million to achieve approximately 50 percent abatement in the Great Southern alone.

It is clear from these results that the current farming system of the Great Southern has few economical management options for greenhouse gas abatement. The introduction of policy measures for decreasing emissions in this region would be politically unpopular and, in the absence of swift and innovative technical advancement that provides farmers in the region with economical management alternatives, such polices would cause the farms to become bankrupt and be replaced by other land uses.

The limitations of the analysis are first, the use of a single period equilibrium model which means that no account is taken implicitly for variations in the system (e.g. seasonal and price variations). To address this issue, the dynamic nature of certain aspects of the system likely to affect the analysis (i.e. sheep prices) is included through sensitivity analysis. Secondly, the use of the single period equilibrium model does not account for adjustment costs required in altering the optimal enterprise mix. These adjustment costs are unlikely to be great, as the most probable changes (changes of rotation to increase crop production) require little increase in managerial skills or capital outlay, at least for minor changes in enterprise mix. A third limitation of the analysis is that monitoring and compliance costs are not captured. These costs are likely to be high given present technology and knowledge. Lastly, the production system is only considered for one agricultural region in Australia. However, results can be 
generalised for other regions where edaphic and climatic factors mean that agriculture in the region is dominated by sheep production.

This analysis has highlighted several potential topics for further research. One is the investigation of other managerial options for greenhouse gas abatement that are available to Great Southern farmers. Examples of these alternative options are the introduction of commercial trees for carbon dioxide sequestration and the use of antimethanogen vaccines that decrease methane emissions from sheep. Another area for further research is the analysis of policy options for greenhouse gas abatement for a crop dominant farming system so that the efficiency and effectiveness of these options can be compared with other Australian farming systems. 


\section{References}

ABARE, 1992. Farm Surveys Report 1992. Australian Bureau of Agricultural and Resource Economics, Canberra.

ABARE, 1998. Emission Trading in Australia. Rep. No. 98.1. Australian Bureau of Agricultural and Resource Economics, Canberra.

ABS, 1997. Agstats: Small Area Agricultural Commodity Data. Australian Bureau of Statistics, Perth.

AGO, 1999a. National Emissions Trading: Establishing the Boundaries. Rep. No. 1. Australian Greenhouse Office, Canberra.

AGO, 1999b. National Emissions Trading: Issuing the Permits. Rep. No. 2. Australian Greenhouse Office, Canberra.

AgWA, 2000. Farm Budget Guide 2000. Farm Weekly, South Perth.

Bouwman, A. F., 1994. Direct emission of nitrous oxide from agricultural soils. Rep. No. 773004004, National Institute of Public Health and Environmental Protection, Bilthoven, The Netherlands. Cited in NGGI (1998f).

Howden, S. M., White, D. H., McKeon, G. M., Scanlan, J. C., and Carter, J. O., 1994. Methods for exploring management options to reduce greenhouse gas emissions from tropical grazing systems. Climatic Change 30, 1-19.

Kingwell, R. S., and Pannell, D. J. (Eds.), 1987. MIDAS, a bioeconomic model of a dryland farm system. Pudoc, Wageningen.

Marsh, S. P., and Pannell, D. J., 1998. Agricultural extension policy in Australia: The good, the bad and the misguided. Paper presented at the 42nd Annual Conference of the Australian Agricultural and Resource Economics Society, 19-21 January 1998, University of New England, Armidale, Australia.

Morrison, D., Kingwell, R., Pannell, D., and Ewing, M., 1986. A mathematical programming model of a crop-livestock farm system. Agricultural Systems 20, 243-268.

Morrison, D. A., and Young, J., 1991. Profitability of increasing lambing percentage in the Western Australian wheatbelt. Australian Journal of Agricultural Research 42, 227 241.

NGGI, 1998a. Workbook for Carbon Dioxide from the Biosphere. Australian Greenhouse Office: National Greenhouse Inventory Committee, Canberra.

NGGI, 1998b. Workbook for Fuel Combustion Activities Stationary Sources. Australian Greenhouse Office: National Greenhouse Inventory Committee, Canberra.

NGGI, 1998c. Workbook for Fugitive Fuel Emissions Fuel Production, Transmission, Storage and Distribution. Australian Greenhouse Office: National Greenhouse Inventory Committee, Canberra.

NGGI, 1998d. Workbook for Industrial Processes and Solvent and Other Product Use. Australian Greenhouse Office: National Greenhouse Inventory Committee, Canberra.

NGGI, 1998e. Workbook for Livestock. Australian Greenhouse Office: National Greenhouse Inventory Committee, Canberra.

NGGI, 1998f. Workbook for Non-Carbon Dioxide Gases from the Biosphere. Australian Greenhouse Office: National Greenhouse Gas Inventory Committee, Canberra.

NGGI, 1998g. Workbook for Transport Mobile Sources. Australian Greenhouse Office: National Greenhouse Inventory Committee, Canberra.

NGGI, 1998h. Workbook for Waste. Australian Greenhouse Office: National Greenhouse Inventory Committee, Canberra.

Pannell, D. J., 1996. Lessons from a decade of whole-farm modelling in Western Australia. Review of Agricultural Economics 18, 373-383. 
Pannell, D.J., Malcolm, L.R. and Kingwell, R.S., 1998. Are we risking too much?

Perspectives on risk in farm modelling. Agricultural Economics 23, 69-78.

Schmidt, C., and Pannell, D. J., 1996. Economic issues in management of herbicide resistant weeds. Review of Marketing and Agricultural Economics 64, 307-308.

UNFCCC, 1997. Kyoto Protocol to the United Nations Framework Convention on Climate Change. Available from the UNFCCC website: http://www.unfccc.de/.

Wills, I., 1997. Economics and the Environment: A Signaling and Incentives Approach. Allen and Unwin, Sydney.

Young, J., 1995. MIDAS: Model of an Integrated Dryland Agricultural System: Manual and Documentation for the Great Southern Model Version GS92-3. Centre for Legumes in Mediterranean Agriculture, Nedlands. 


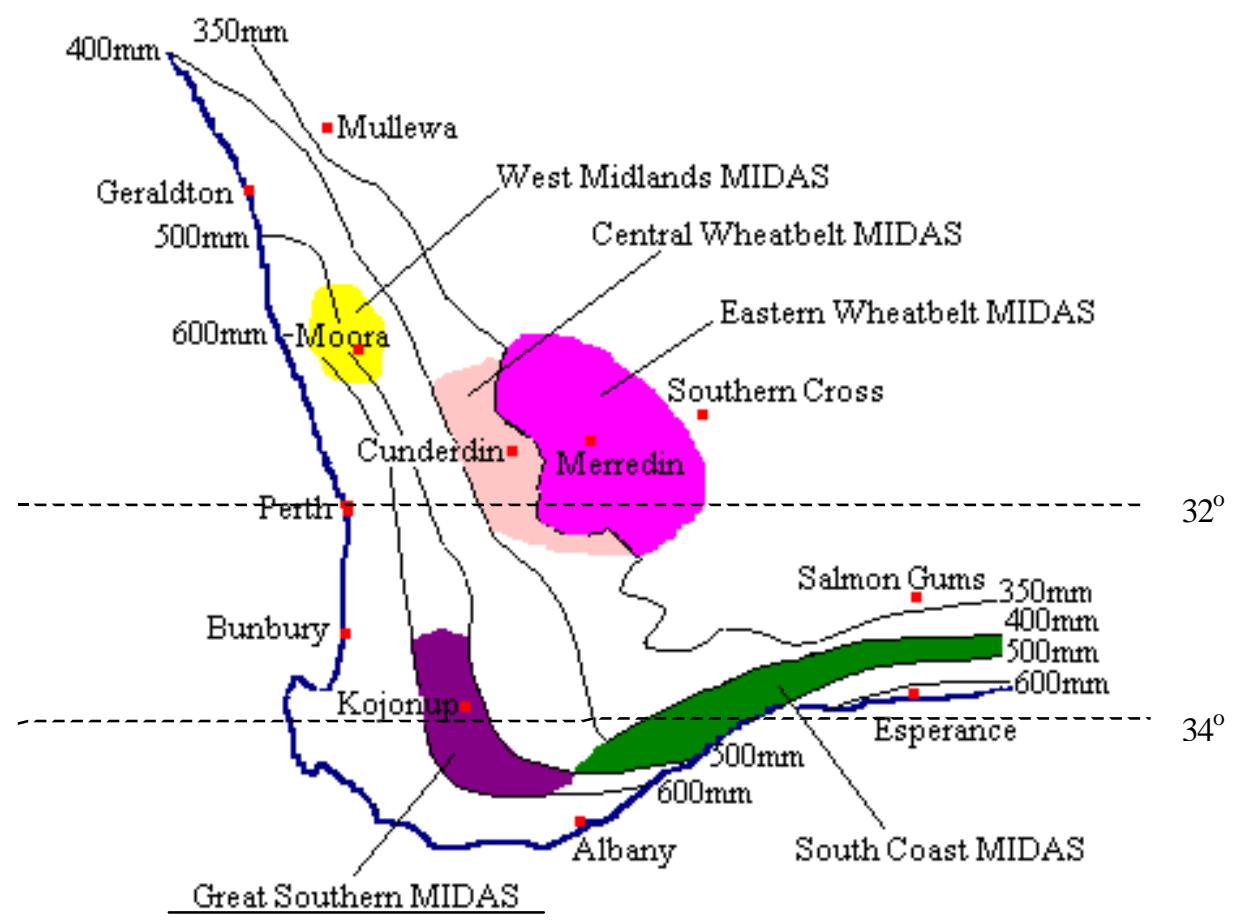

Figure 1

Areas of Western Australia covered by MIDAS

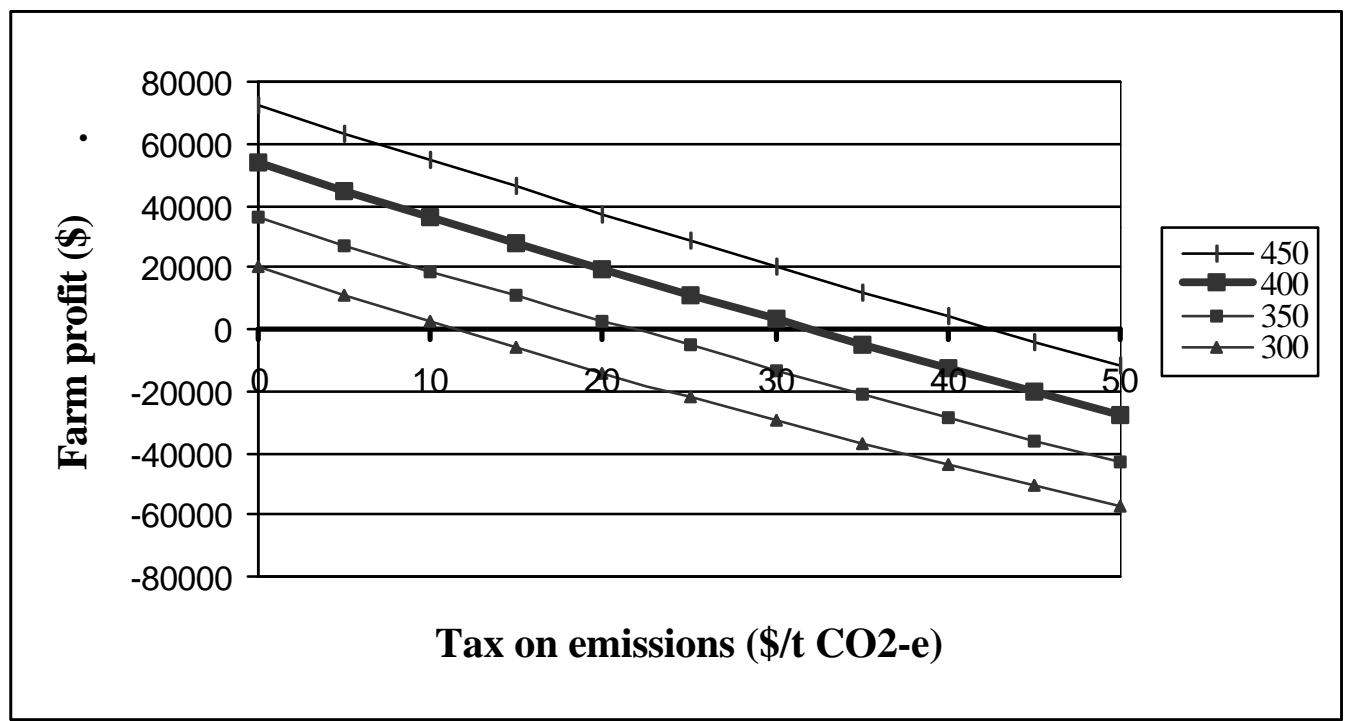

Figure 2

The impact of different levels of a tax on greenhouse gas emissions on farm profit for varying wool prices (wool price is in $\mathrm{c} / \mathrm{kg}$ greasy) 


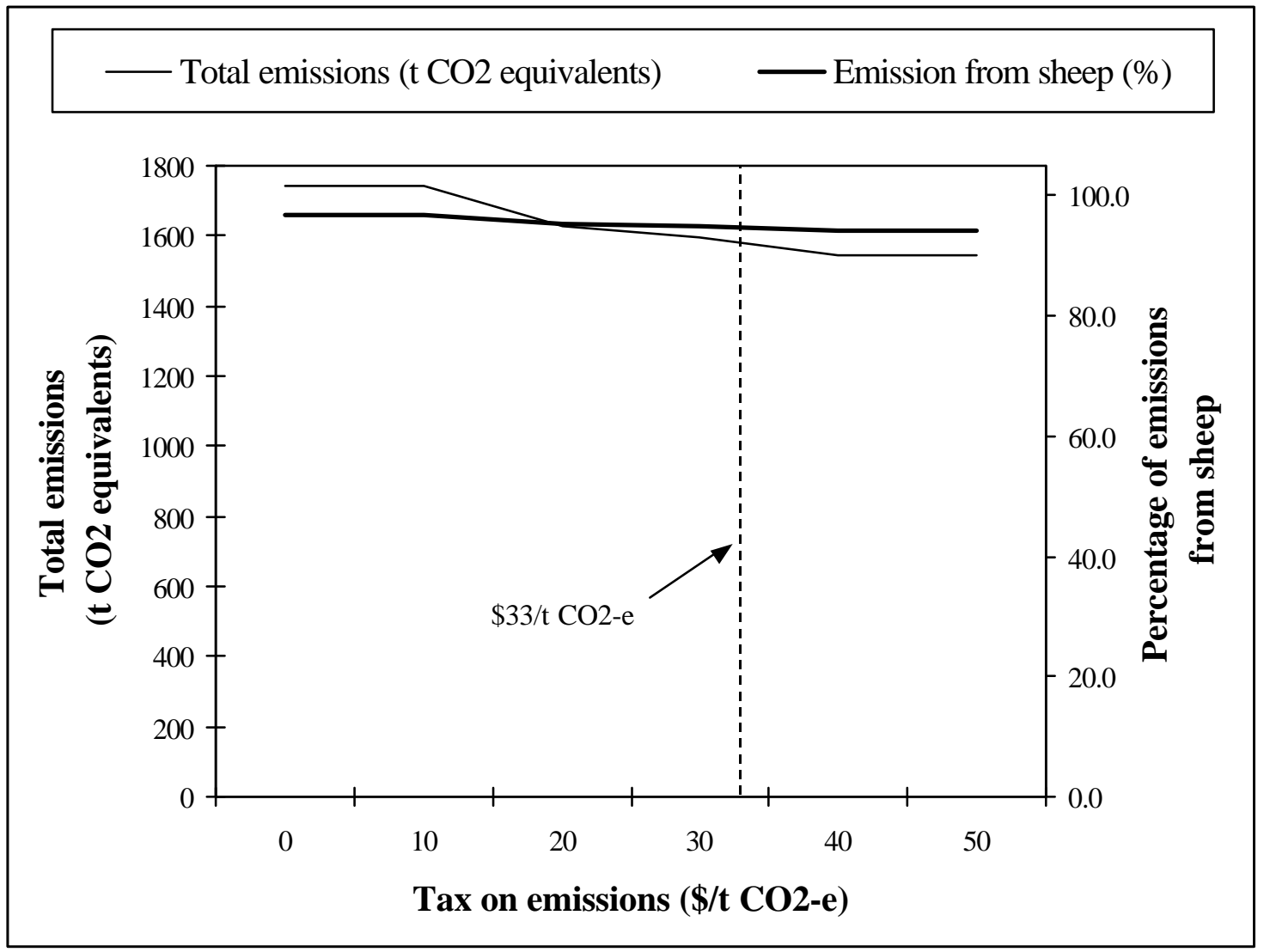

Figure 3

Total emissions and the proportion of emissions from sheep under different emission tax levels

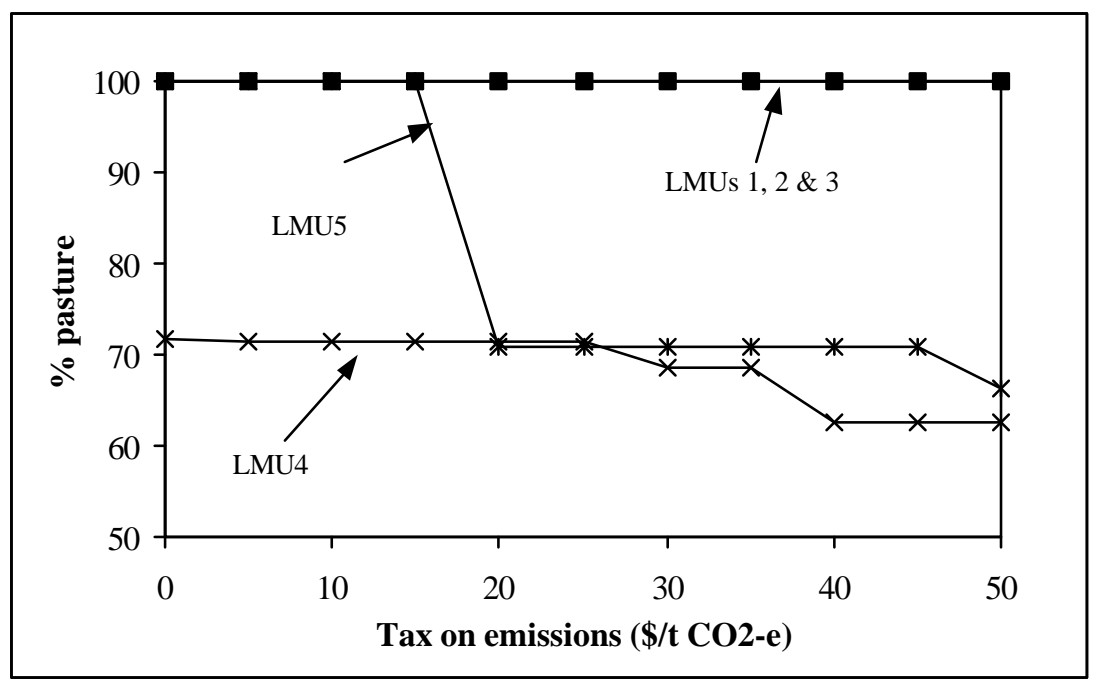

Figure 4

The proportion of each land management unit in pasture under different emission tax levels. 


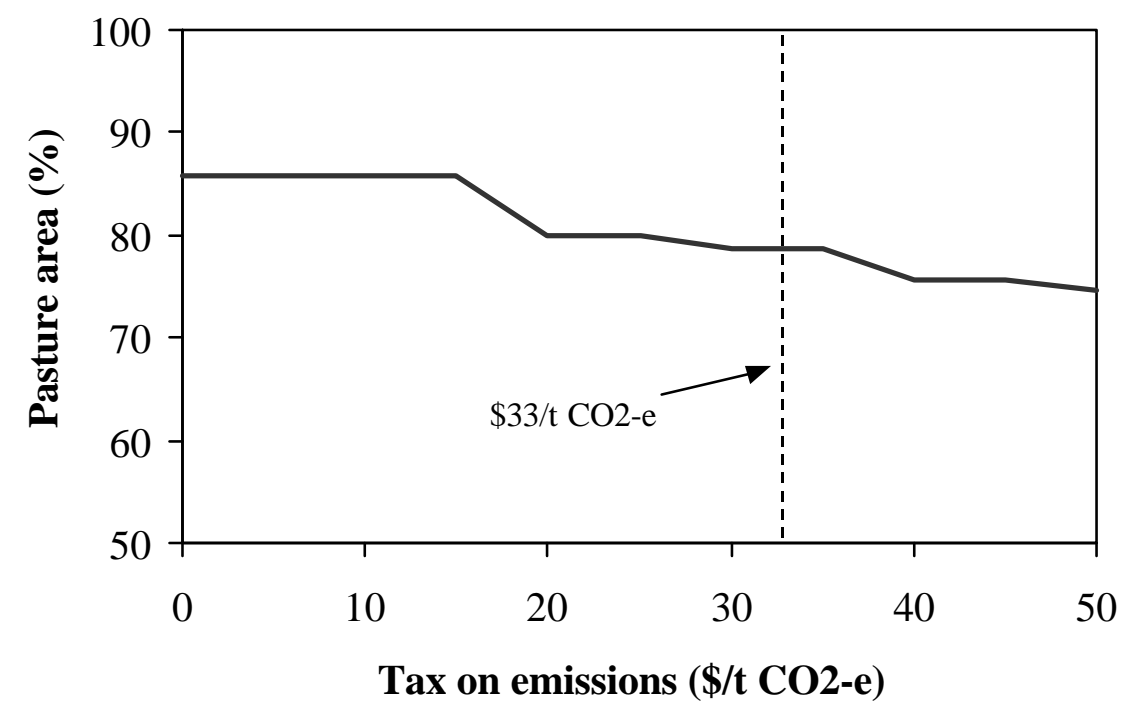

Figure 5

The proportion of the whole farm in pasture under different emission tax levels.

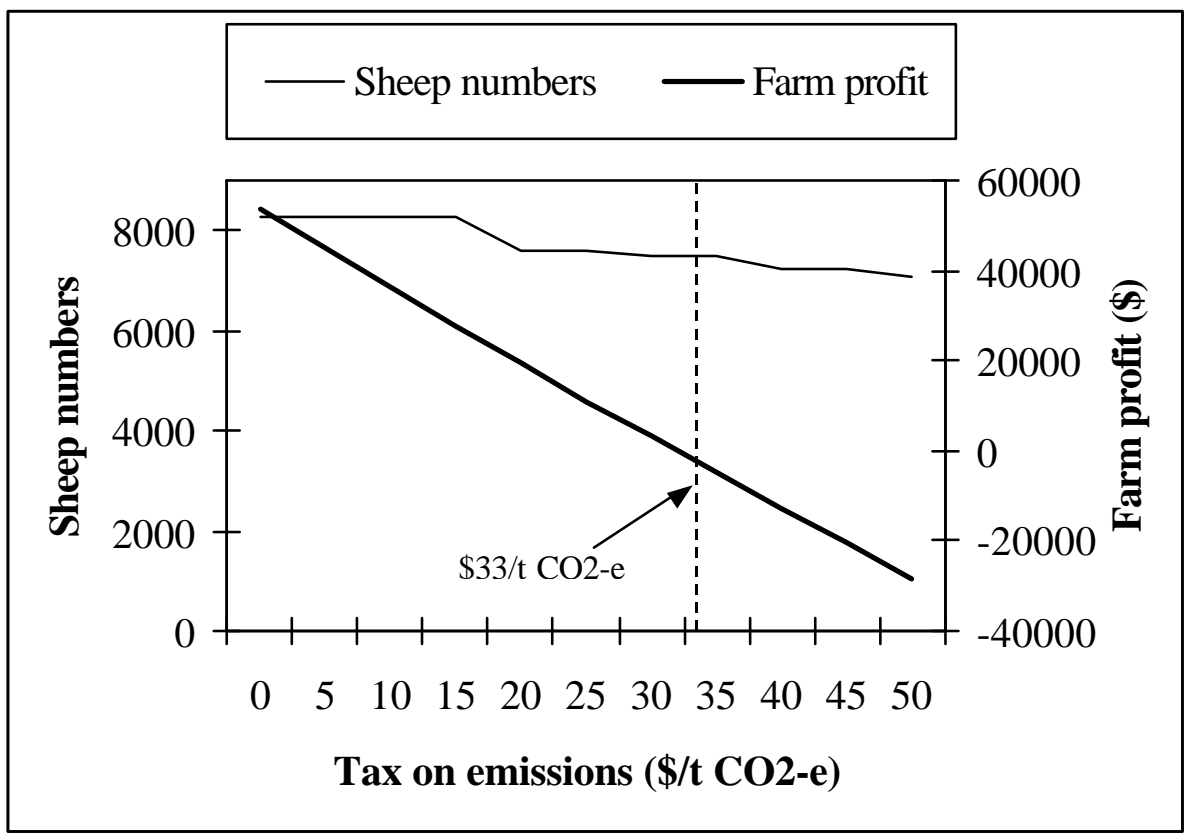

Figure 6

Sheep numbers and farm profit for different emission tax levels 


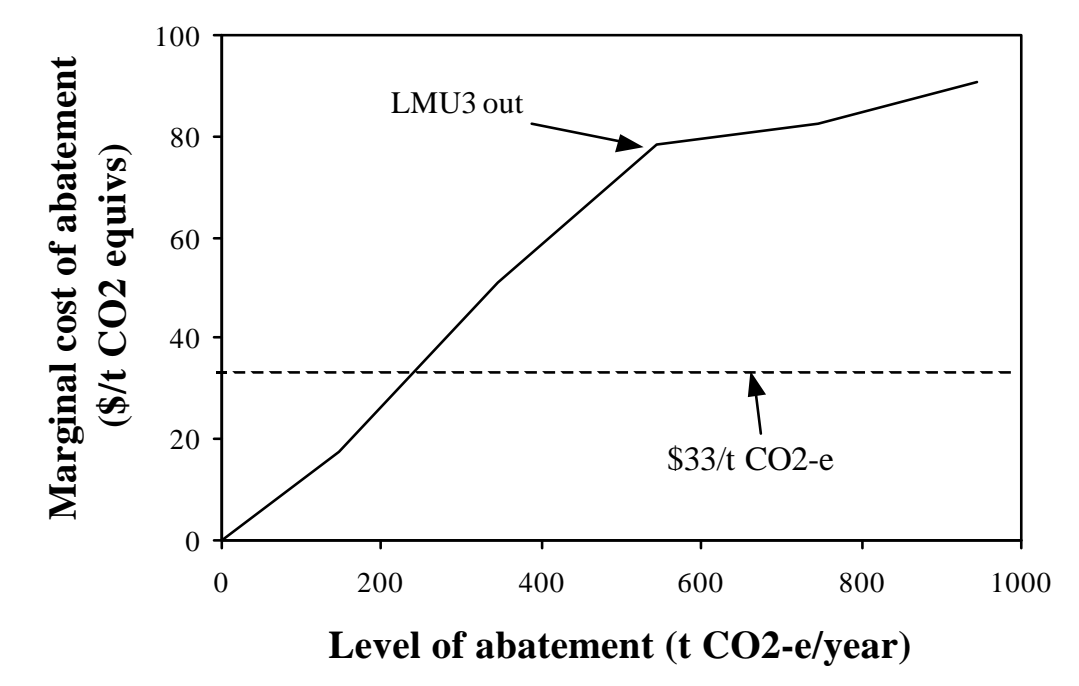

Figure 7

Marginal cost of abatement for different abatement levels

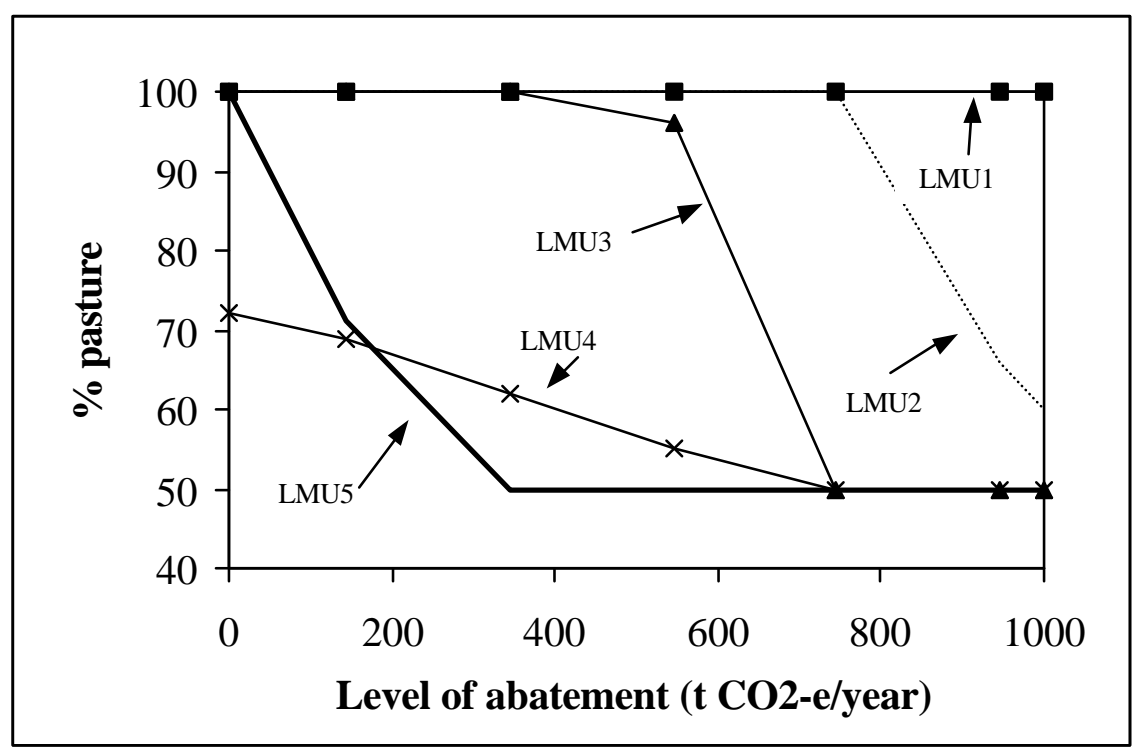

Figure 8

Pasture area versus abatement levels under emission restrictions 


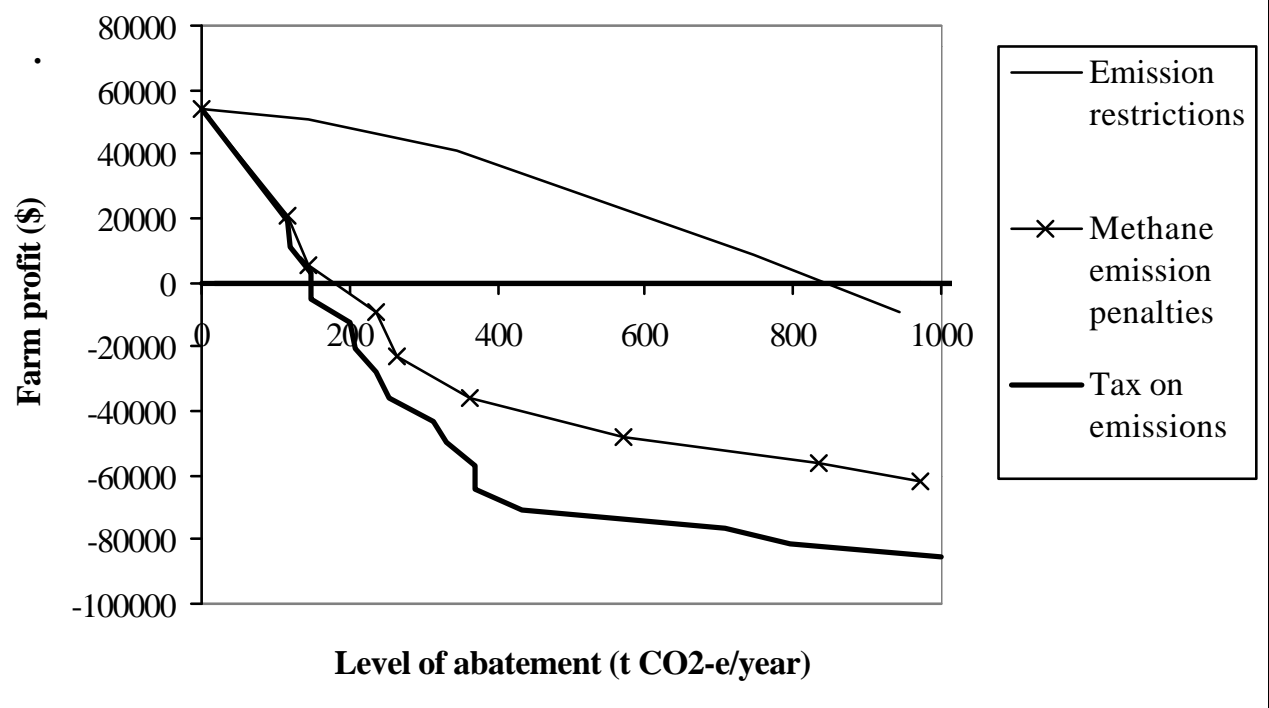

Figure 9

Farm profit versus level of abatement

Table 1

Summary statistics for the Great Southern region and the Western Australian agricultural zone

\begin{tabular}{lcc}
\hline & $\begin{array}{c}\text { Great Southern } \\
\text { region only }\end{array}$ & $\begin{array}{c}\text { Western Australia } \\
\text { agricultural zone }\end{array}$ \\
\hline Total area of agricultural holdings ('000 ha) & 1,100 & $18,800(6 \%)$ \\
Total number of agricultural holdings & 1,000 & $10,900(9 \%)$ \\
Total number of sheep and lambs ('000 hd) & 4,500 & $23,100(20 \%)$ \\
Total area sown to crop ('000ha) & 200 & $5,600(3 \%)$ \\
Total value of livestock products (\$ '000) & 97,200 & $619,100(16 \%)$ \\
Total value of crops (\$ '000) & 65,200 & $2,154,900(3 \%)$ \\
Total value of agriculture (\$ '000) & 217,500 & $3,283,900(7 \%)$ \\
\hline
\end{tabular}

\footnotetext{
12 Proportion of Great Southern in the total Western Australian agricultural zone in brackets.
} 
Table 2

MIDAS soil types

\begin{tabular}{ccc}
\hline Soil class & Description & Area (ha) \\
\hline LMU1 & $\begin{array}{c}\text { Shallow saline sands over heavy } \\
\text { gleyed or mottled clay. }\end{array}$ & 100 \\
(Saline soils) & $\begin{array}{c}\text { Deep sands often waterlogged over } \\
\text { LMU2 }\end{array}$ & 150 \\
grey gleyed clay. & 50 \\
LMUterlogged soils) & $\begin{array}{c}\text { Deep sands but not waterlogged over } \\
\text { mottled clay. }\end{array}$ & 500 \\
(Deep sands) & $\begin{array}{c}\text { Gravels and sandy gravels to 50cm } \\
\text { over clay or gravelly clay. }\end{array}$ & 200 \\
(Sandy gravels) & $\begin{array}{c}\text { Sandy loam, loamy sand over clay. } \\
\text { Rock outcropping in landscape. }\end{array}$ & \\
LMU5 & &
\end{tabular}

Table 3

Rotational options in Great Southern MIDAS

\begin{tabular}{cc} 
Rotations on all land management units & $\begin{array}{c}\text { Rotation on land management units } \\
4 \text { and } 5 \text { only }\end{array}$ \\
\hline $\begin{array}{c}\text { PC, PPC, 4PC, 8PC, 5PCC, 5PLC, 5PCCC, } \\
\text { 5PCLC, PPPP, 5PS }\end{array}$ & 5 PNC \\
\hline
\end{tabular}

Table 4

Global-warming potential of greenhouse gasses relative to carbon dioxide

\begin{tabular}{cccccc}
\hline & \multicolumn{5}{c}{ Greenhouse Gas } \\
& $\mathrm{CO}_{2}$ & $\mathrm{CH}_{4}$ & $\mathrm{~N}_{2} \mathrm{O}$ & $\mathrm{CO}$ & NMVOC \\
\hline Global-warming & 1 & 21 & 310 & 1 & 1 \\
potential relative to $\mathrm{CO}_{2}$ & & & & & \\
\hline
\end{tabular}

Table 5

Calculation of levels of nitrous oxide emissions per tonne of applied fertiliser

\begin{tabular}{cccccc}
\hline Fertiliser & $\%$ nitrogen & $\begin{array}{c}\mathrm{kg} \mathrm{N} / \mathrm{t} \\
\text { fertiliser }\end{array}$ & $\begin{array}{c}\text { Emission } \\
\text { factor }\end{array}$ & $\begin{array}{c}\text { Conversion } \\
\text { factor }\end{array}$ & $\begin{array}{c}\mathrm{kg} \mathrm{N}_{2} 0 \text { emitted / } \\
\text { tonne fertiliser }\end{array}$ \\
\hline DAP & 17.5 & 175 & 0.0125 & 1.57 & 3.43 \\
Urea & 46 & 460 & 0.0125 & 1.57 & 9.03 \\
Agras & 17.5 & 175 & 0.0125 & 1.57 & 3.43 \\
Data source & (AgWA, 2000) & (Bouwman, 1994) & \\
\hline
\end{tabular}

\footnotetext{
${ }^{13} \mathrm{P}=$ Pasture, $\mathrm{C}=$ Cereal, $\mathrm{L}=$ Lupin, $\mathrm{F}=$ Field Peas, $\mathrm{S}=$ Fodder Crop, $\mathrm{N}=$ Canola
} 
Table 6

Fuel use for two out of the 14 MIDAS operations (L/ha) ${ }^{14}$

\begin{tabular}{cccccc}
\hline Operation & LMU1 & LMU2 & LMU3 & LMU4 & LMU5 \\
\hline Seeding (No Till) & 5.3 & 4.5 & 4.5 & 4.9 & 4.1 \\
Harvesting & 22.5 & 22.5 & 22.5 & 22.5 & 22.5 \\
\hline
\end{tabular}

Source: Young (1995)

Table 7

Fuel burning factors

\begin{tabular}{ccccc}
\hline Fuel type & $\begin{array}{c}\text { Energy density } \\
(\mathrm{MJ} / \mathrm{L})\end{array}$ & $\begin{array}{c}\text { Grams of } \mathrm{CO}_{2} \\
\text { per MJ }\end{array}$ & $\begin{array}{c}\text { Proportion } \\
\text { oxidised }\end{array}$ & $\begin{array}{c}\mathrm{CO}_{2} \text { emissions } \\
(\mathrm{kg} / \mathrm{L})\end{array}$ \\
\hline Diesel & 38.6 & 69.7 & 0.99 & 2.66 \\
Petrol & 34.2 & 66.0 & 0.99 & 2.23 \\
\hline
\end{tabular}

Source: NGGI (1998g)

Table 8

Stubble burning factors (the total factor is multiplied by the stubble yield to calculate the mass of residue that is burnt)

\begin{tabular}{lcc}
\hline & Cereals & Other \\
\hline Fraction of residue remaining at time of burning $\left(S_{i}\right)$ & 0.50 & 0.50 \\
Dry matter content $\left(D M_{i}\right)$ & 0.90 & 0.80 \\
Burning efficiency $\left(Z_{i}\right)$ & 0.96 & 0.96 \\
Fraction of the annual production of crop that is burnt $\left(F_{i}\right)$ & 0.23 & 0.23 \\
Total factor (product of all other factors) & 0.10 & 0.09 \\
\hline
\end{tabular}

Source: Young (1995)

Table 9

Stubble burning emission factors

\begin{tabular}{lccccc}
\hline & $\mathrm{CH}_{4}$ & $\mathrm{~N}_{2} \mathrm{O}$ & $\mathrm{NO}_{\mathrm{x}}$ & $\mathrm{CO}$ & $\mathrm{NMVOC}^{15}$ \\
\hline Carbon mass fraction $\left(\mathrm{CC}_{i}\right)$ & 0.40 & 0.40 & 0.40 & 0.40 & 0.40 \\
Elemental N:C ratio $\left(\mathrm{NC}_{i}\right)$ & 1.000 & 0.008 & 0.008 & 1.000 & 1.000 \\
Emission factor $\left(\mathrm{E}_{i}\right)$ & 0.0035 & 0.0076 & 0.2100 & 0.0780 & 0.0091 \\
Elemental to molecular mass & 1.33 & 1.57 & 3.29 & 2.33 & 1.17 \\
conversion factor $\left(\mathrm{C}_{i}\right)$ & & & & & \\
\hline
\end{tabular}

Source: NGGI (1998f)

\footnotetext{
${ }^{14}$ The number of operations used is optimised implicitly in GSM. Details are available from authors on request.

${ }^{15}$ Non Methane Volatile Organic Carbon
} 
Table 10

Predicted carbon dioxide equivalent permit prices facing Australia in 2010 under various Kyoto-consistent scenarios $\left(\mathrm{A} \$ \text { per tonne of } \mathrm{CO}_{2}\right)^{16}$

\begin{tabular}{cccc}
\hline Model & Independent abatement & Developed country trading & Global trading \\
\hline G-Cubed (a) & 44 & 38 & na \\
G-Cubed (b) & na & 16 & 5 \\
GTEM (a) & 191 & 48 & na \\
GTEM (b) & 87 & 37 & na \\
SGM & 55 & $32-44$ & $9-11$ \\
MERGE & na & 48 & 34 \\
POLES & na & 47 & 14 \\
World Scan & na & 8 & na \\
GREEN & na & 28 & 10 \\
AIM & 40 & 27 & 18 \\
\hline
\end{tabular}

See AGO (1999b) for reference details.

Table 11

Zero-profit abatement levels for each abatement policy

\begin{tabular}{lcc}
\hline Abatement policy & Zero-profit abatement level \\
\hline Tax on total emissions & $\mathrm{t} \mathrm{CO}_{2}$-e & $\%$ \\
Tax on methane emissions only & 150 & 8 \\
Emission restrictions & 180 & 10 \\
\hline
\end{tabular}

${ }^{16}$ GTEM (b) results relate to $\mathrm{CO}_{2}, \mathrm{~N}_{2} \mathrm{O}$ and $\mathrm{CH}_{4}$ emissions and abatement opportunities relating to energy and agricultural activities. Other modelling results reported refer to combustion-related $\mathrm{CO}_{2}$ emissions.

To convert from $\$ /$ tonne of $\mathrm{CO}_{2}$ to an equivalent cost per tonne of carbon, divide estimates by 44/12. Most studies refer to 1995 US dollars, GTEM results are reported in 1992 US dollars. To convert to \$A an exchange rate of A $\$ 1.54$ per US\$ was used. 